\title{
Configuration Management of information systems in Peruvian Goverment organizations
}

\author{
Elizabeth Mendoza, Ciro Rodríguez, Doris Esenarro
}

\begin{abstract}
Having a well-defined control of the change processes in the configuration management in the software development life cycle, before and after being put into production environment, implies an effort of development personnel and an additional cost in the maintenance system. The objective of this paper is to establish the guidelines to regulate the activities and tasks during the process of development and maintenance of software-based systems in order to control the changes, integrity and traceability of its configuration, for this purpose it is taken as a reference the peruvian technical standards NTP-ISO/IEC 12207: 2016 for Software and systems engineering, NTPISO/IEC 27001: 2014 for Information security management systems and the methodology MÉTRICA version 3 for the systematization of life cycle of the software activities. The proposal defines the roles and responsibilities, the activities of each thread and the use of control templates, the validation of the was achieved through the analysis of three software systems with results that show that there is a better organization in the development, maintenance, control of the versions of the elements and the percentage of error in the configuration.
\end{abstract}

Keywords: Software Configuration Management, information system, maintenance, change control, NTP-ISO / IEC 27001:2014, NTP-ISO / IEC 12207: 2016

\section{INTRODUCTION}

Many public organizations in Perú do not have a welldefined process to control software changes in their information systems, before and after putting them into production. The lack of a process of management of the configuration of the software systems, has as a consequence the instability and insecurity of the product and its components, which implies a double effort on the part of the development personnel and an additional cost in the maintenance of the system, during the software development process and the implementation of procedures, methodologies and guides problems have been found that need to be corrected or minimized, this is where the process of managing the software configuration of the systems plays a very important role, considering that it is one of the key processes for the proper functioning of the information systems of organizations that perform software engineering, since it allows a better organization of software development and maintenance during the life cycle of the software process.

According to [1] "The Software Configuration Management Process establishes and maintains the integrity of the support elements of a process or project and make them available to interested parties". In [2] it is explained

Revised Manuscript Received on 14 September, 2019.

Elizabeth Mendoza, NationalUniversity Federico Villarreal. (Email:emendoza@ reniec.gob.pe)

Ciro Rodríguez, NationalUniversity Mayor de San Marcos. (Email: crodriguezro@unmsm.edu.pe) desenarro@unfv.edu.pe)
Doris Esenarro, NationalUniversity Federico Villarreal. (Email:

that the purpose of this process area is to establish and maintain the integrity of work products using the identification, control, status and audits of the configuration Pressman in [3] shows the breakdown of the knowledge area Software configuration management of SWEBOK V3 with the knowledge areas characterizing the practice of software engineering.

In [4], the METRIC V3 methodology offers organizations a tool for the systematization of activities that support the software life cycle where "configuration management is to maintain the integrity of the products obtained during the development of the systems of information, ensuring that there are no uncontrolled changes in the development of the system with the correct version, therefore, among the software configuration elements, there is not only executable code and source, but also data models, process models, specifications of requirements, tests ".

According to [5], Annex A.9.4.5 on the Control of access to the source code of the program, it is explained that access to the source code of the program must be restricted and strictly controlled, since it can be vulnerable if it is not adequately protected, compromising systems and quickly destroying the value of the business.

\section{IIMETHOOLOGY}

According to [6] Software Engineering (IS) is the discipline or area of computer science that offers methods and techniques for the development and maintenance of quality software In spite of all efforts made, in the successive stages of development and management activities of software projects, problems occur as: lack of reliability, need for permanent maintenance, etc. Dynamics of software development processes require a constant update of techniques and technologies.

According to [7], the control of the documents generated from the process of implementing an Information System helps to manage, declare and organize the latest versions, giving legibility in the documents during the implementation life cycle. As in [8], is also important consider the cryptographic key management guide to define and implement appropriate key management procedures, using algorithms that adequately protect confidential information and planning in advance possible changes and the availability of computer techniques through a general approach.

It is also important to consider the methodologies as in [9] for the planning and implementation of an integral IT architecture that combines software with high-level servers that can host systems capable of providing support and continuity of IT services in critical areas of the 


\section{CONFIGURATION MANAGEMENT OF INFORMATION SYSTEMS IN PERUVIAN GOVERMENT ORGANIZATIONS}

organization as well as the optimization of the resources necessary for its administration which influence configuration and change management

According to [10], the generation of efficient and quality software products without sacrificing time or costs is the necessary that the actors involved in the process can have all the information related to the project and that the version control systems support the software development process, facilitating the management of version control of the source code files generated by the developers and providing the tools to merge and generate a new version of a project, without causing loss of data or file locks, as well as recover previously generated files, which can be used to correct system errors.

In [11], the emergence of Global Software Development GSD has created difficulties for the practice of Software Configuration Management (SCM), the author has proposed tools to reduce such difficulties, to do this has specifically identified the environment, contributing to: Synthesize SCM tools in GSD and identify the current trend of SCM tools in the software development environment.

\section{MATERIALS AND METHODS}

On the materials and methods, the following were taken into account:

Research Techniques and Instruments:

Direct observation: monitoring of the main development activities in the process of the Configuration Management of the information systems was carried out, in order to detect the current state.

Data Analysis:

Logical techniques of content or qualitative analysis, to obtain conclusions.

Unstructured Interviews: who develop and implement software, in order to obtain detailed information on this activity.

Referential Review:

Standards NTP-ISO/IEC 12207:2016, NTP-ISO/IEC 27001:2014; Metric V3.

\section{Instruments:}

- $\quad$ NTP-ISO / IEC 12207: 2016.

- Metric V3.

- $\quad$ NTP-ISO / IEC 27001:2014

- $\quad$ Bizagi Modeler tool.

- Computer requirements.

- Meeting Minutes.

- Development methodology.

- $\quad$ MS Office package.

- Laptop with internet access.

- Office resources.

\section{Proposed model:}

The configuration management model of the information systems, aims to establish and maintain the integrity of the products and services developed, as well as the control of changes throughout the software life cycle. The elements are: the information of an element and software products, its version, status, trace of its evolution, technical goal that software developers seek to achieve, for this it is

A series of interviews were conducted with personnel

documentation related to the analysis, design, construction, implementation and acceptance of the information system.

Figure 1, shows the processes and activities of the management of the configuration of the computer systems: Roles and responsibilities of configuration management, this phase describes identifying the roles and responsibilities of the entire management process in which they are: IT Manager, Project Leader, Configuration Management Leader, Software Configuration Management Specialist, Technical Documentation Management Specialist, Database Configuration Management Specialist, Quality Assurance Leader, Quality Assurance Specialist, Data Center Supervisor. Of the computer systems and of the technical documentation: In this phase the process of change requests and production sources is indicated.

Related to computer systems and the technical documentation: In this phase the process of change requests and production sources is indicated. Upon the change requests, the development area receives the change request, evaluates and assigns the developer for its attention, the developer must record the changes made for each item and / or software products, technical documentation in a control $\log$ of changes, as shown in Figure 1.

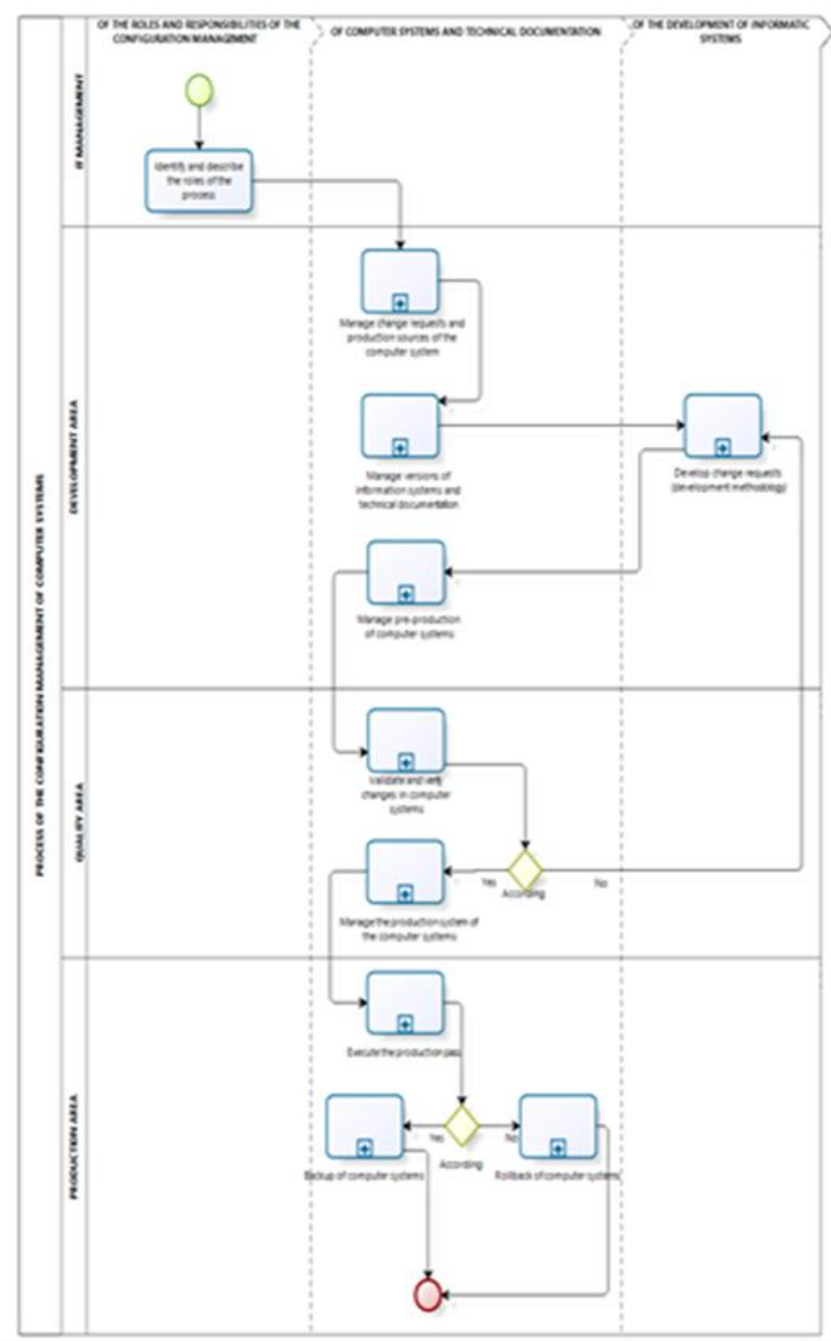

Figure 1. Process of the Management of the Configuration of the Computer Systems 
In Figure 2., changes made to information systems are recorded as; the system, sub system, module, sub module, type of device, date of request, version, description of the change, information system affected, responsible for the change, date of update and the location of the change.

Annotations are made in the binnacle of change control.

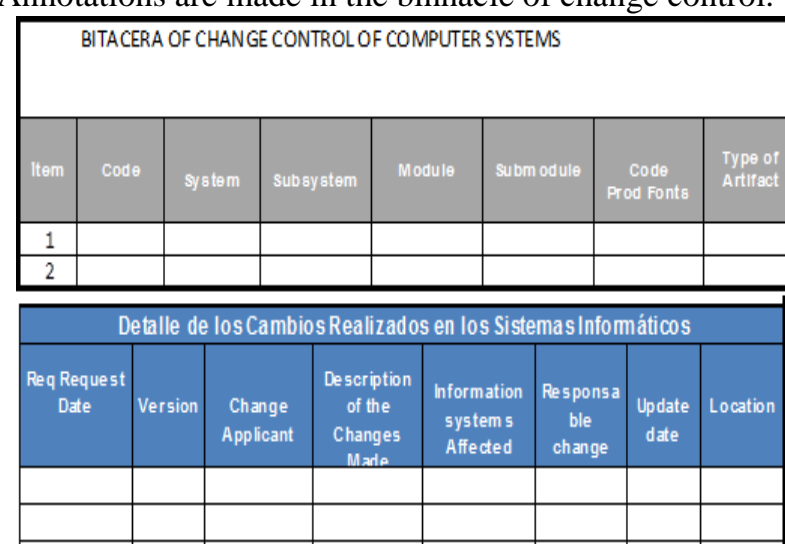

Figure 2. Change control log of computer systems.

When requesting sources, the IT project leader or authorized persons in their absence will be the only ones who can request production sources. The software configuration specialist and the technical documentation specialist will provide the requested sources, also record the item's output in the version control register.

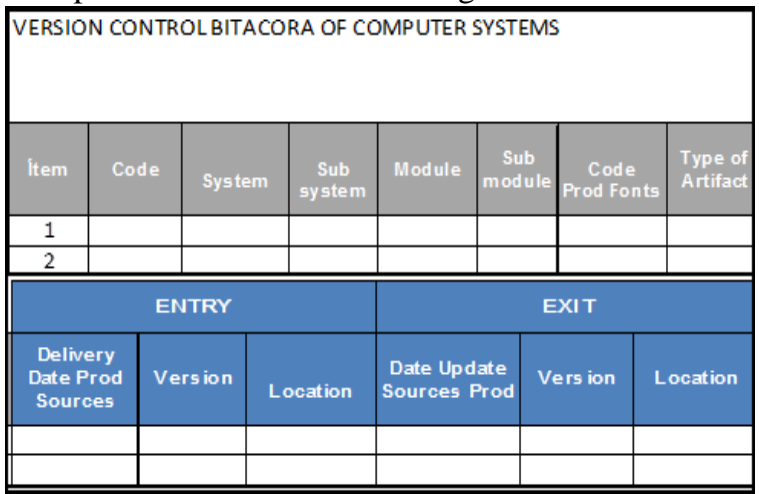

Figure 3.Version control log of computer systems.

Figure 3 shows the control record of system versions, subsystem, module, submodule, type of artifact; at the entrance: the version, location; and on the way out: the product update date, version and location.

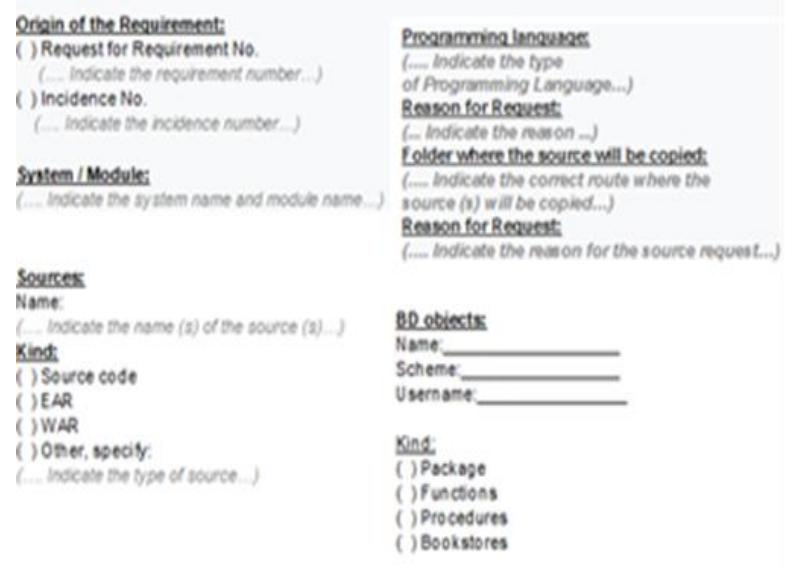

Actions to be camied eut:-..- Indicate the cons idverations and actions to follow for the attention.

Figure 4.Request for sources.
Figure 4 shows the origin request, according to [6], where the control A.9.4.5 "The access control to the source code of the programs must be restricted", therefore, must be requested through a document or email indicating: the origin of the requirement, system / module, name of the source, type of source, programming language, name of the database, scheme and the place where the information was requested will be copied.

\section{Origin of the Requirement: \\ ( ) Request for Requirement No. (.... Indicote the requirement number...) ( ) Incidence No. (.... Indicote the incidence number...)}

\section{System / Module: (.... Indicate the system name and module name...) Reason for Request: (.... Indicote the reoson for the request...) Document Version: (.... Indicate the updoted version...)

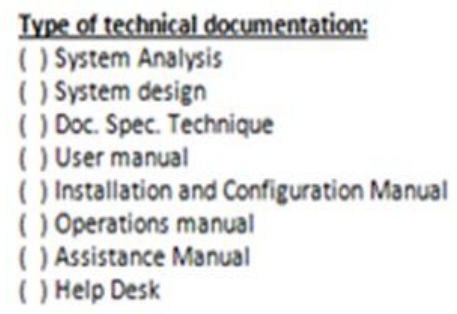 \\ Folder where the technical documentation will be copied: ( - Indicote the correct route where the documentotion will be copied.) \\ Actions to be carried out: \\ (- Indicote the considerations and octions to follow for the ottention.)}

\section{Figure 5. Request for technical documentation}

The document in Figure 5, as in the previous one, shows that the technical information is requested through a document or email: origin of the requirement, system / module, the version of the document and the location where the information will be copied.

On the management of versions Figure 6 shows development to pre-production: little significant change: increase by one hundredth of the version if you do not pass the pre-production test. No change: the tenth remains the same. Significant change: increase 1 in version number.

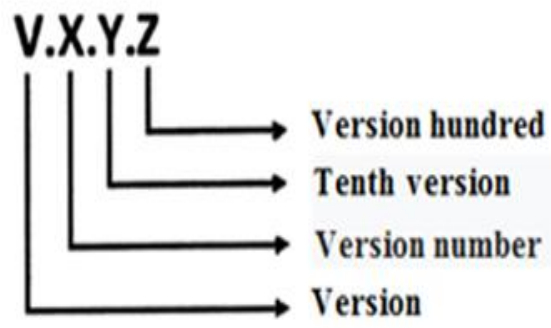

Figure 6.Versions to pre-production development.

In the preproduction development of the version management, if there is a significant change, it increases by one hundredth of the version or else, passes the preproduction test. No changes: the tenth remains the same and with a significant change: it increases 1 in the version number. 


\section{CONFIGURATION MANAGEMENT OF INFORMATION SYSTEMS IN PERUVIAN GOVERMENT ORGANIZATIONS}

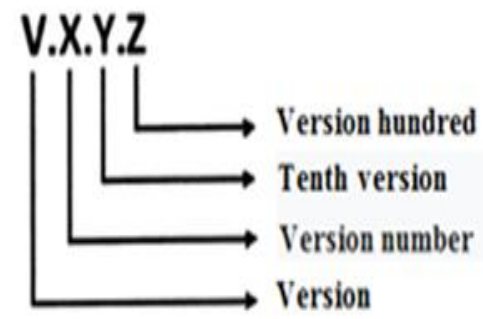

Figure 7. Versions pass pre-production to production.

The database configuration management specialist will track the versions of the objects, procedures, functions, database packages and the version record of the computer systems. The quality control specialist will control the versions of the sources, executable from the pre-production environment as in Figure 7. The configuration management specialist will control the versions of the production environment.

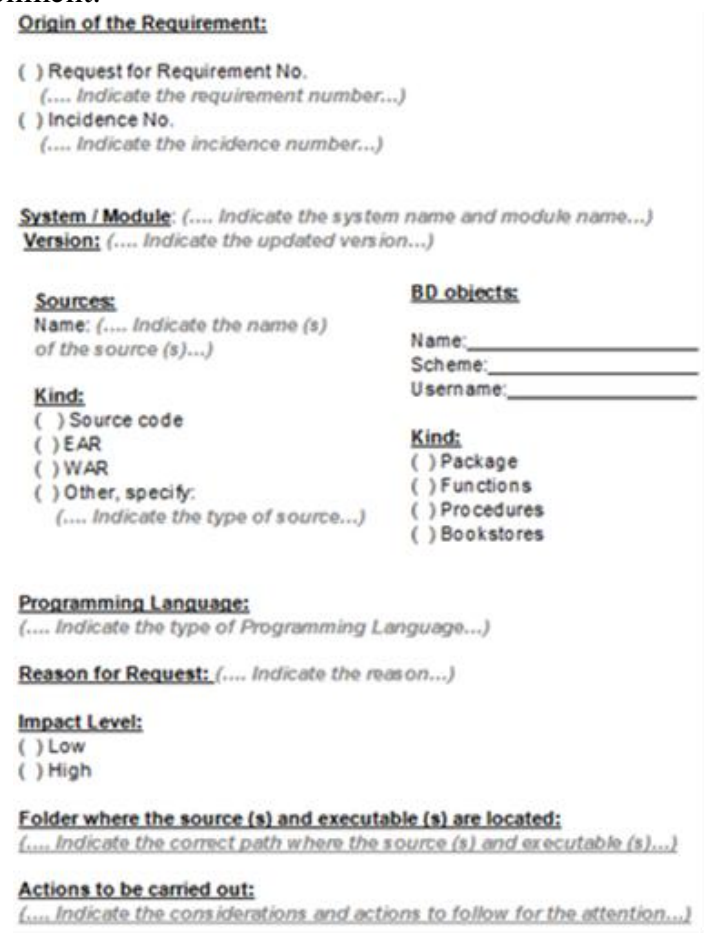

Figure 8.Preproduction request.

In Figure 8, the pre-production pass is requested through a document or email.

When requesting a pre-production pass, the IT project leader will request the pre-production pass for elements, executables, objects, procedures, functions, packages, etc.

The quality assurance area will verify and validate the change request, if everything is agreed it will manage the production pass, if you have any observations, it will be sent to the development area for correction.

Upon the production pass, the quality assurance specialist will issue the compliance of the requirement, using a format.

In Figure 9, the certificate of conformity is shown by the quality team, giving the conformity for the production pass.

Likewise, he will coordinate with the leader of the computer project and the software configuration management specialist for the production pass, a quality assurance specialist will send all the elements for the production pass.

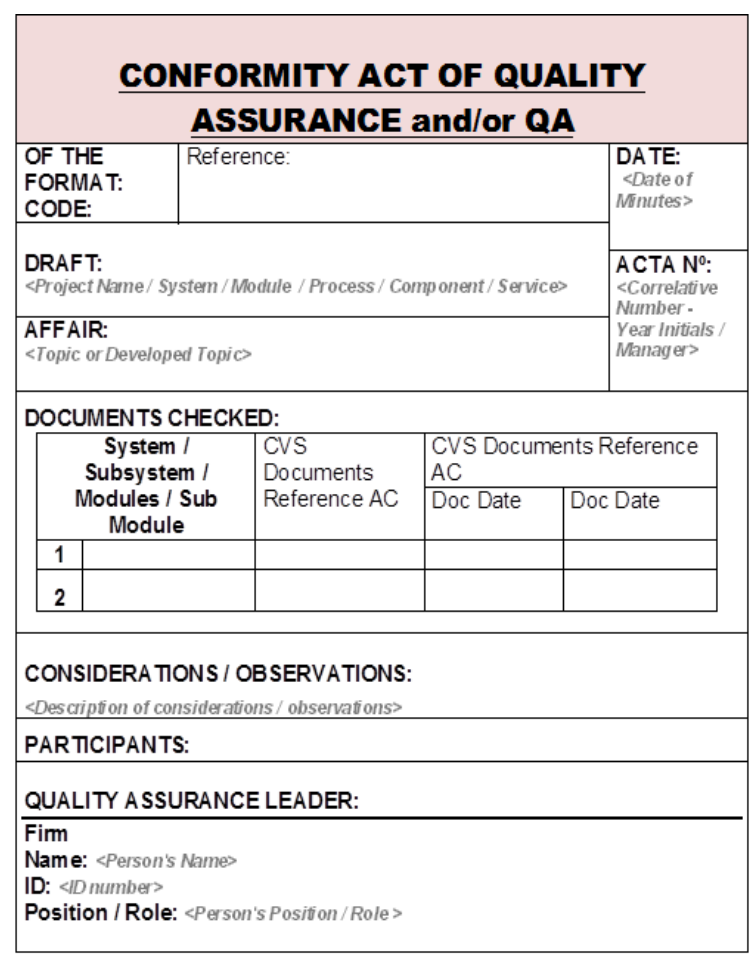

Figure 9.Certificate of Conformity of Quality Assurance and / or Quality Control.

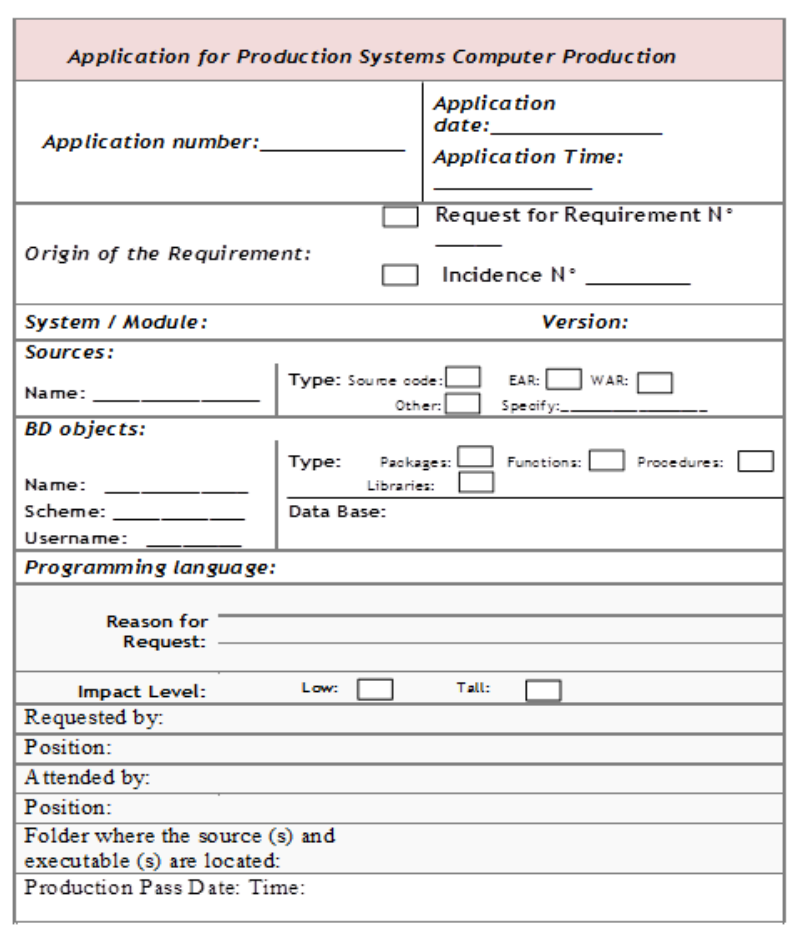

Figure 10. Production pass request.

Figure 10, shows the application certificate for the production pass, which contains the necessary fields to control configuration revisions.

The leader of the software configuration management will execute the production pass if there is an error in the deployment automatically perform the rollback request as in Figure 11, otherwise the computer center supervisor will perform the backup process of the elements of the computer systems.

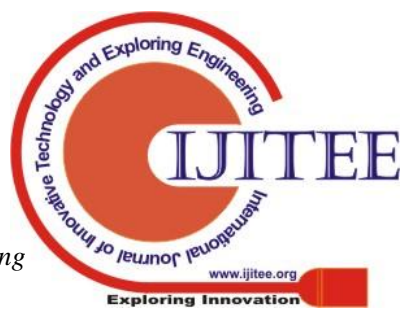




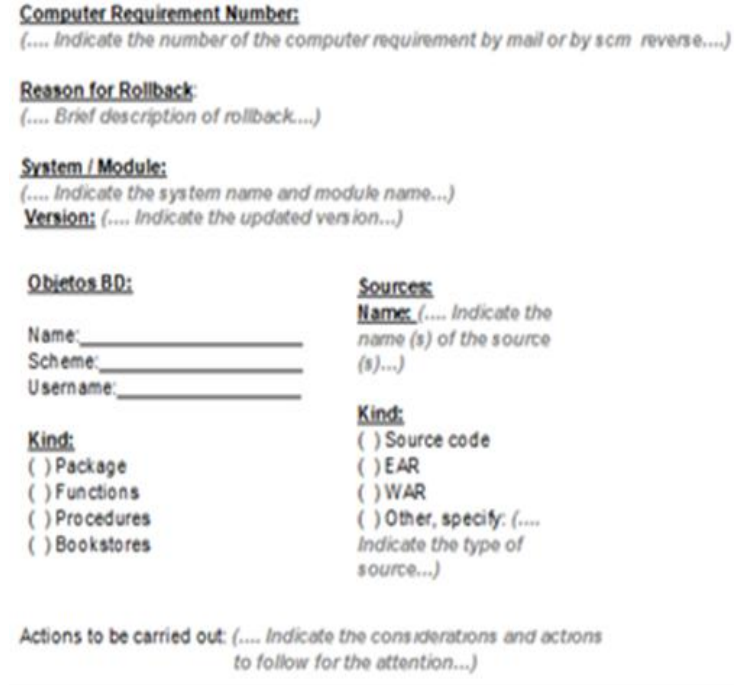

Figure 11.Rollback request.

\section{RESULTS}

For the start-up of the moving process: meetings were held with the IT Management, as a result the baseline of the elements generated by the process was identified, defined and established.

Regarding the development of the process: it was carried out together with the areas involved to agree the procedures, responsible and verify that another process is not affected; generate collaborative methodologies; workflow creation; modification of the old configuration management process.

About the training: the new procedure for its application was carried out to the areas involved.

For the implementation of the start-up of the moving process: Computer requirements were performed:

- Modifications and versions of the elements are controlled.

- The states of the elements and the modifications are registered and reported.

- Ensure that the elements are complete and consistent.

- $\quad$ The storage, handling and delivery of the elements are controlled.

- $\quad$ Errors in production start-up.

Table 1.Comparison configuration process.

\begin{tabular}{|l|l|l|}
\hline Issue & $\begin{array}{l}\text { Amountbefore } \\
\text { theProcess }\end{array}$ & $\begin{array}{l}\text { Amountafterth } \\
\text { eProcess }\end{array}$ \\
\hline $\begin{array}{l}\text { The development team } \\
\text { does not have the latest } \\
\text { version of the software } \\
\text { elements. }\end{array}$ & 03 & 0 \\
\hline Error in thesources in the & 60 & 20 \\
\hline $\begin{array}{l}\text { Observation production } \\
\text { technical } \\
\text { documentation. }\end{array}$ & 03 & 10 \\
\hline $\begin{array}{l}\text { Configuration errors in } \\
\text { the } \\
\text { environment. }\end{array}$ & 0 & 01 \\
\hline QA in & 20 & 03 \\
\hline Qualityassurement. & 0 & 03 \\
\hline $\begin{array}{l}\text { Incidence } \\
\text { production. }\end{array}$ & \\
\hline
\end{tabular}

Having completed the process of the Configuration Management of Systems, a considerable improvement computer requirement can be evidenced, minimizing the errors of the sources, technical documentation, configuration of the production environment, production incidents, higher product quality in information systems, as shown in Table I.

\section{DISCUSSION}

Standard [1] indicates that the software configuration management process establishes and maintains the integrity of the support elements of a process or project and makes them available to interested parties; for state organizations, it is applicable as long as the organization is committed, respecting the procedures efficiently, also in these organizations it is more complicated to apply [4], because it is sequential, and currently the software life cycle has a tendency To be agile, therefore the validation of the Configuration Management of a lightweight model for the development of small business software, should mention that the quality areas and the personnel that will carry out the configuration process must remain separate from the development area, not to influence.

\section{ACKNOWLEDGEMENTS}

Acknowledgments to the research group led by Dr. Ciro Rodríguez, and engineer Anani Niño de Guzmán for her great experience in configuration management.

\section{REFERENCES}

1. Peruvian Technical Standard NTP-ISO / IEC 12207: 2016 Software and Systems Engineering, software life cycle process,

2. V. Esterkin y C. Pons "Quality evaluation in software development model driven by models", Inter-American Open University, Argentina, 2017.

3. S. Rodriguez Corvalan, "Process Implementation Configuration Management and Assets of the ITIL® service in an IT department of a University", 2017.

4. MÉTRICA Versión 3.: Metodología de Planificación y Desarrollo de Sistemas de Información . Guías de Referencia, de Técnicas y del Usuario . Ministerio para las Administraciones Públicas . Editorial TECNOS, Madrid.

5. Peruvian Technical Standard NTP-ISO / IEC 27001 INFORMATION TECHNOLOGY. Security techniques Information security management systems.

6. M. Daniele, MUva, P. Martelloto, G. Picco; "Application of CASE tools to the teaching of Software Engineering: Software Configuration Management and Functional Testing", National University of Río Cuarto, Argentina, 2010.

7. R. Martelo, J.Madera y Andrés D. Betín, "Software for Document Management, a Modular Component of the Information Security Management System (ISMS)", University of Cartagena, Colombia, 2015.

8. EB. Barker, A. Roginsky (2019) Transitioning the Use of Cryptographic Algorithms and Key Lengths. (National Institute of Standards and Technology, Gaithersburg, MD), NIST Special Publication (SP) 800- 131A, Rev. 2. https://doi.org/10.6028/NIST.SP.800-131Ar2 


\section{CONFIGURATION MANAGEMENT OF INFORMATION SYSTEMS IN PERUVIAN GOVERMENT \\ ORGANIZATIONS}

9. Reyes, C. Rodriguez and D. Esenarro (2019) «Hyper Converged Systems Applied (HSA) Methodology to Optimize the Process of Technological Renewal in Data Centers,» International Journal of Recent Technology and Engineering (IJRTE), vol. 8, Issue-2S11, p. 4052, September 2019.

10. L.Tello, C. Sosa, D. Tello,"Review of the Version Control Systems used in software development", USBMed Engineering Magazine, ISSN-e 2027-5846, Vol. 3, No. 1, p. 74-81, 2012.

11. S.S.M.Fauzi, A.J.Suali, W.A.W.M.Sobri,"A State of the Art: Software Configuration Management Tools for Global Software Development, International PostGraduate Conference on Applied Science \& Physics 2017, IOP Conf. Series: Journal of Physics: Conf. Series 1049 (2018) 012006, doi :10.1088/1742$6596 / 1049 / 1 / 012006$

\section{AUTHORS PROFILE}

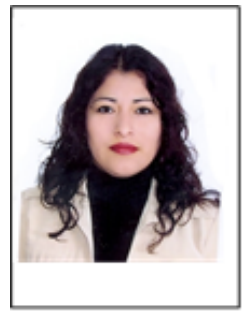

Elizabeth Mendoza Aliaga Student of the Doctorate of Systems Engineering of the National University Federico Villarreal, with experience in Software Quality Assurance and Control, with studies in Systems Engineering.

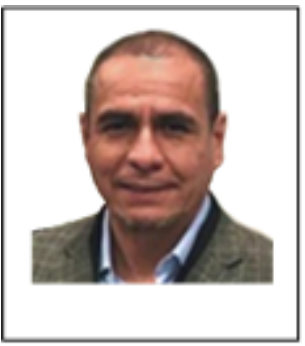

Ciro Rodriguez RodriguezProfessor at the School of Software Engineering at the National University Mayor de San Marcos and also at the Computer Science School and Graduate School of the National University Federico Villarreal, with science studies at the Abdus Salam International Center for Theoretical Physics (ICTP) and the United States Particle Accelerator School (USPAS).

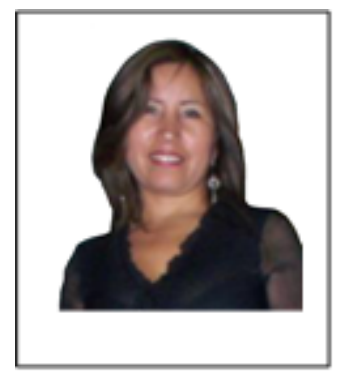

\section{Doris}

Esenarro

VargasProfessor at the Faculty of Environmental Engineering and Graduate School of the National University Federico Villarreal, with studies in System Engineering, Architecture and Environmental Engineering. 